\title{
O ATIVO DAS METODOLOGIAS ATIVAS: CONTRIBUIÇÕES DA TEORIA HISTÓRICO- CULTURAL PARA OS PROCESSOS DE ENSINAR E APRENDER NA EDUCAÇÃO SUPERIOR
}

\author{
SOLANGE MARIA ALVES ${ }^{1}$ \\ ORCID: https://orcid.org/0000-0002-5222-6066 \\ CARLA ROSANE PAZ ARRUDA TEO ${ }^{2}$ \\ ORCID: https://orcid.org/0000-0002-1534-6261
}

\begin{abstract}
RESUMO: O texto em tela traduz um esforço de teorização decorrente de pesquisa em torno das chamadas metodologias ativas de ensino-aprendizagem na educação superior, mais precisamente no contexto da formação em saúde, empreendendo uma análise pautada pelos pressupostos teóricometodológicos da concepção histórico-cultural de desenvolvimento humano. Assume-se, particularmente, o marco teórico da Escola de Vigotski, com as contribuições de Lev S. Vigotski e Alexei Leontiev, a partir de sua Teoria da Atividade. Objetivamente, perseguimos desenvolver um quadro teórico-conceitual capaz de mediar outras leituras sobre o que se pode chamar de ativo nas metodologias ativas, desde uma perspectiva histórico-cultural. $\mathrm{O}$ alcance desse objetivo se orienta pelos pressupostos do materialismo histórico-dialético, matriz de referência da teoria histórico-cultural, o que demanda a observância de um objeto em movimento e multideterminado. Possíveis resultados desse empreendimento sinalizam afirmativamente para a possibilidade de pensar as chamadas metodologias ativas no escopo da teoria histórico-cultural de desenvolvimento psíquico humano. Nossas (in) conclusões iniciais apontam possibilidades de pensar, organizar e propor atividades de ensino e de aprendizagem na educação superior, compreendendo o ativo como movimento de cognição que se efetiva na apreensão de objetivações do gênero humano e de constituição de processos de subjetivação por meio da atividade tipicamente humana.
\end{abstract}

Palavras-chave: Desenvolvimento humano, Formação profissional em saúde, Teoria da atividade.

\section{THE ACTIVE OF ACTIVE METHODOLOGIES: CONTRIBUTIONS FROM HISTORIC-CULTURAL THEORY TO TEACHING AND LEARNING PROCESSES IN HIGHER EDUCATION}

\begin{abstract}
This text is an effort of theorization, resulting from a research about the designated active teaching-learning methodologies in higher education, more particularly in the context of health education, developing an analysis based on the theoretical-methodological assumptions of the historical-cultural conception of human development. The theoretical option is based on Vigotski School theoretical

\footnotetext{
${ }^{1}$ Universidade Federal da Fronteira Sul (UFFS). Chapecó, SC, Brasil. <solange.alves@uffs.edu.br>

${ }^{2}$ Universidade Comunitária da Região de Chapecó (Unochapecó). Chapecó, SC, Brasil. <carlateo@unochapeco.edu.br> Educação em Revista|Belo Horizonte|v.36|e229610|2020
} 
background, with the contributions of Lev S. Vygotsky and Alexei Leontiev, based on their Theory of Activity. Objectively, we intend to develop a theoretical and conceptual framework able to mediate other readings about what can be called active in active methodologies, from the historical-cultural perspective. The scope of this objective is guided by the assumptions of historical-dialectical materialism, the reference matrix of historical-cultural theory, which demands the observance of a moving and multidetermined object. Possible results of this project indicate affirmatively to the possibility of thinking about the designated active methodologies in the scope of the historical-cultural theory of human psychic development. Our initial conclusions indicate possibilities of to think, organize and propose teaching and learning activities in higher education, understanding the active as a movement of cognition that is effective in the apprehension of human objectivations and the constitution of subjectivation processes through human typically activity.

Keywords: Human development, Professional training in health, Activity theory.

\section{EL ACTIVO DE METODOLOGÍAS ACTIVAS: CONTRIBUCIONES DE LA TEORÍA HISTÓRICO-CULTURAL A LOS PROCESOS DE ENSEÑANZA Y APRENDIZAJE EN LA EDUCACIÓN SUPERIOR}

RESÚMEN: El presente texto traduce un esfuerzo de teorización resultante de pesquisa acerca de las llamadas metodologías activas de enseñanza-aprendizaje en la educación superior, más precisamente en el contexto de la formación en salud, emprendiendo un análisis orientado por los presupuestos teóricosmetodológicos de la concepción histórico-cultural de desarrollo humano. Se supone, particularmente, el marco teórico de la Escuela de Vigotski, con las contribuciones de Lev S. Vigotski y Alexei Leontiev, a partir de su Teoría de la Actividad. Objetivamente, perseguimos desarrollar un cuadro teórico-conceptual capaz de mediar otras lecturas sobre lo que se puede llamar de activo en las metodologías activas, desde una perspectiva histórico-cultural. El alcance de ese objetivo se orienta por los presupuestos del materialismo histórico-dialéctico, matriz de referencia de la teoría histórico-cultural, lo que demanda la observación de un objeto en movimiento y multideterminado. Posibles resultados de ese emprendimiento señalan afirmativamente para la posibilidad de pensar las llamadas metodologías activas en el alcance de la teoría histórico-cultural de desarrollo psíquico humano. Nuestras (in) conclusiones iniciales apuntan posibilidades de pensar, organizar y proponer actividades de enseñanza y de aprendizaje en la educación superior comprendiendo el activo como movimiento de cognición que se efectiva en la percepción de objetivaciones del género humano y de constitución de procesos de subjetivación por medio de la actividad típicamente humana.

Palabras clave: Desarrollo humano, Formación profesional en salud, Teoría de la actividad. 


\section{INTRODUÇÃO}

A práxis pedagógica na educação superior vem, como a escola em geral, se defrontando com um conjunto de novos desafios, dentre os quais se destacam, sobremaneira, aqueles relativos ao processo pedagógico propriamente dito, no âmbito da relação entre ensino e aprendizagem. Novos perfis humanos, constituídos na complexidade das relações sociais, de trabalho, produção e significação da vida contemporânea, acessam a educação superior, trazendo consigo jeitos de ser e dinâmicas cognitivas bastante diferentes da tradição acadêmica.

Por outro lado, essas transformações, que vêm ocorrendo em um ritmo acelerado, fomentadas, sobretudo, pelo advento das novas tecnologias e das mudanças radicais na base técnica de produção, especialmente desde a emergência da microeletrônica e, mais recentemente, da cibernética, das redes sociais, das virtualidades da chamada revolução 4.0 ou internet das coisas, ao mesmo tempo que são manifestações da atividade criadora do ser humano, são também elementos modificadores das relações que, por sua vez, produzem culturas na mesma medida em que produzem novas demandas ao modelo social fundado no liberalismo de mercado. Nesse contexto, novas demandas são também apresentadas a outros movimentos - políticos, sociais e pedagógicos - que se colocam na disputa dialética por outras possibilidades de ser e de estar no mundo, impondo a esses movimentos desafios antes inimagináveis.

Desse cenário, emergem demandas educacionais. Ao mundo e às relações contemporâneas (de mercado ou não), já não cabem concepções e políticas educacionais alicerçadas em modelos fixos de ensinar e de aprender. A dinâmica e a fluidez das relações sociais, de trabalho e produção, exigem um humano flexível, autônomo, capaz de decidir com lucidez, crítica e rapidez, capaz de liderar, de cooperar e de atuar coletivamente, o que requer o desenvolvimento de habilidades de relacionamento, de comunicação e de postura, implicadas no aprendizado de conhecimentos, procedimentos, valores e atitudes (saber, saber ser, fazer e conviver). Impõe-se, assim, à educação superior, rever seus formatos de ensino-aprendizagem. A formação do perfil humano que veio sendo delineado pelas demandas sociais, de mercado e do mundo do trabalho, foi se instando e dando a direção das políticas de formação superior.

$\mathrm{Na}$ área da formação profissional e do ensino em saúde, que nos interessa aqui, não tem sido diferente. As últimas quatro décadas têm se caracterizado pela implementação de programas que visam a qualificar a formação profissional nesse campo, por meio da articulação interdisciplinar das áreas da Saúde e da Educação, essenciais para uma formação que contemple os princípios do Sistema Único de Saúde (SUS) (BATISTA et al., 2015; CYRINO et al., 2015). O que se busca, nesse âmbito, é uma formação que considere o conceito ampliado de saúde, estabelecido como direito, e que, assim, supere por incorporação a visão biomédica, que

[...] está presente na construção da área da saúde como campo de aplicação de conhecimentos e técnicas fundamentados nas ciências biológicas e médicas. Ao circunscrever saúde à ausência de doença, [...] desconsidera-se uma dimensão mais ampla que é a da saúde como potência para lidar com a existência. Embora tal concepção de saúde não exclua as demais, nem seja incompatível com elas, não é a que predomina na atenção à saúde, mesmo quando se afirma que a saúde está relacionada a outras expressões do humano, tais como a vitalidade e a felicidade. (CZERESNIA; MACIEL; OVIEDO, 2013, p. 12).

Desde o início dos anos 2000, quando foram publicadas as primeiras Diretrizes Curriculares Nacionais (DCN) para cursos de graduação em saúde (BRASIL, 2001a; 2001b; 2001c), as políticas nesta área têm, em geral, fechado questão na formação de um perfil generalista, humanista, crítico e reflexivo, capacitado a atuar de acordo com o sistema de saúde, pautado em princípios éticos, no processo saúdedoença, em diferentes níveis de atenção, com ações de promoção, prevenção, recuperação e reabilitação à saúde, na perspectiva da integralidade da assistência.

Dentre os diversos movimentos estabelecidos para dar conta do que está posto nas DCN e, dessa forma, garantir uma formação que atenda aos princípios do SUS, há que se destacar o Programa Nacional de Reorientação da Formação Profissional em Saúde (Pró-Saúde), dispositivo proposto em 2005 pelo Ministério da Educação, juntamente com o Ministério da Saúde, e que produziu, ao longo dos 
anos, mudanças relevantes nos processos de formação profissional na área. O programa tinha por objetivo reorientar a formação, assegurando uma abordagem integral do processo saúde-doença, promovendo transformações nos processos de geração de conhecimentos, ensino e aprendizagem e de prestação de serviços à população, e estabelecia que esse processo precisava ser desenvolvido a partir de três eixos: orientação teórica, cenários de práticas e orientação pedagógica (BRASIL, 2007; BRASIL, 2005). No eixo Orientação Pedagógica, o programa preconizava o uso de metodologias ativas no processo de ensino-aprendizagem. Estas metodologias deveriam propor desafios a serem superados pelos estudantes que lhes possibilitassem ocupar o lugar de sujeitos na construção do conhecimento (BRASIL, 2007).

As políticas e dispositivos de reorientação da formação de profissionais da saúde têm sinalizado para a organização do processo de ensino-aprendizagem a partir de estratégias consideradas dinâmicas e problematizadoras, capazes de produzir um ser humano autônomo, pensante, crítico, colaborativo, ativo no processo de aprender e se desenvolver. Essas proposições, colocadas no horizonte da formação profissional, requerem, por sua vez, outro perfil de docência, agora não mais centrada no professor ou professora, mas no aluno como ser ativo, autônomo. Não cabe mais, aqui, o professor ou a professora da aula expositiva, do silêncio, da transmissão do conhecimento, que submete o aluno a ouvir, anotar e reproduzir o que lhe foi transmitido. Demanda-se uma docência menos dura, mais flexível e, ao menos aparentemente, talvez, mais dialógica, donde elevam-se e ganham espaço significativo as chamadas metodologias ativas que, a nosso ver e como tem demonstrado a produção sobre o tema ${ }^{3}$, geram, sem dúvida, movimentos e mudanças importantes na dinâmica do processo pedagógico.

Contudo, na avaliação de Conterno e Lopes (2013), a partir de uma análise dos documentos oficiais que orientam a formação profissional em saúde no Brasil, há que se atentar para o fato de que essas recomendações tendem a se constituir como prescrições, ao não declararem seus pressupostos teóricos e concepções de educação e de mundo. As autoras afirmam que

Ao que parece, no campo da saúde, está se forjando um consenso de que as autodenominadas metodologias inovadoras [...] poderão responder, de forma progressista, aos problemas da formação superior dos profissionais da área. Esse enquadramento pode levar à incorporação ou à adesão acrítica, ou apenas à adesão instrumental, sem uma avaliação mais criteriosa e contextualizada dos desdobramentos políticos e pedagógicos para a formação de futuros profissionais da saúde. (CONTERNO; LOPES, 2013, p. 518).

Nesse sentido, ponderamos que as metodologias ativas, precisamente pelo espaço que vêm assumindo nos processos de ensino e de aprendizagem, carecem de um olhar mais crítico e de sustentação teórica, o que, em certa medida e sem a pretensão de esgotar a complexidade do tema, pretendemos que seja uma de nossas contribuições desde o estudo com que estamos nos ocupando. Isso significa dizer que, entre a adesão ingênua e acrítica às metodologias ativas na educação superior em saúde (CONTERNO; LOPES, 2016) e a negação a essa proposta metodológica, nos colocamos, aqui, na posição de quem busca desenvolver um quadro teórico-conceitual capaz de mediar outras leituras sobre o que se pode chamar de ativo nessas metodologias, desde uma perspectiva histórico-cultural, o que constitui o objetivo deste texto. Justificamos nossa proposta, recorrendo, mais uma vez, a Conterno e Lopes (2013, p. 518), quando afirmam que "a discussão central não é de ordem metodológica e sim de ordem epistemológica."

Considerando que a área da formação profissional em saúde tem sido pioneira nesse movimento de valorização e adoção de metodologias ativas de ensino-aprendizagem, argumentamos que ela também tem se apresentado como terreno fértil de problematizações mobilizadoras de pesquisas, como: o que se compreende por metodologias ativas? Como elas têm sido implementadas? O que significa o ativo nas metodologias ativas? Qual o conceito ou concepção de método para as metodologias ativas? Que relações podemos estabelecer entre as metodologias ativas - tal como se apresentam ou são concebidas - e as teorias pedagógicas? Que concepções de humano, formação, conhecimento,

\footnotetext{
${ }^{3}$ Nesse sentido, algumas produções podem ser consultadas, como Batista e Gonçalves (2011), Freitas et al. (2015), Bacich e Moran (2018), entre outras.
} 
aprendizagem e desenvolvimento estão mais fortemente presentes nas metodologias ativas? Que implicações decorrem disso para os indivíduos e para a sociedade? E mais, tendo em vista as distintas e divergentes teorias educacionais, que são, na outra face, concepções de sociedade e de ser humano, como as metodologias ativas se situam nestes contextos? Em face das grandes transformações no âmbito da economia liberal, são as metodologias ativas aportes para o desenvolvimento de perfis humanos adequados a essa lógica? De outro lado, as metodologias ativas podem se vincular a concepções críticas de educação? Essas perguntas mobilizadoras orientam a reflexão aqui empreendida.

Sob este prisma, o presente texto traduz um exercício de refletir sobre as metodologias ativas desde um lugar teórico-metodológico situado no âmbito das teorias críticas da educação, mais especificamente no quadro geral da teoria histórico-cultural de desenvolvimento humano. Neste sentido, perseguimos, aqui, um quadro teórico-conceitual demarcado pela perspectiva histórico-cultural de desenvolvimento humano, capaz de mediar novas leituras e sinalizar modos de organização dos processos de ensino e de aprendizagem no contexto da educação superior que nos ajude a construir possíveis respostas e, de algum modo, contribuir para análises mais aprofundadas e para a construção de bases teóricas sólidas para a qualificação dos processos de ensino e de aprendizagem no contexto da educação superior.

A materialidade para esta reflexão está na problematização da expressão ativo, no âmbito das metodologias ativas. Em termos gerais, a literatura sobre o tema parece considerar que a noção de ativo tem a ver com um certo movimento corporal, mais físico do que intelectual ou cognitivo propriamente dito. A aprendizagem ativa estaria, assim, associada a estratégias pedagógicas mais praticistas do que praxiológicas. Ou, dizendo de outro modo, concebidas como ato de aproximar teoria e prática mais do que como ato de práxis, o que leva, inadequadamente, a uma postura de docência que considera que as metodologias ativas servem para aproximar a prática dos diferentes cenários de atuação profissional com a teoria que se acha dentro dos limites universitários. Essa perspectiva, a nosso ver, conduz a uma interpretação mecanicista de ser humano, de aprendizagem e de prática social.

Compreendendo a aprendizagem ativa como resultado da atividade intelectual de um ser humano situado historicamente, nosso interesse aqui é contribuir para uma reflexão sobre a atividade bumana com base nos aportes da teoria histórico-cultural, especialmente a partir do pensamento de Lev Vigotski e Alexei Leontiev. Nestes termos, nossa preocupação é trazer elementos que auxiliem a problematizar, a refletir criticamente acerca do que pode ser considerado ativo numa metodologia ativa e - porque estamos tratando de formação profissional no âmbito da educação superior e, portanto, de trabalho educativo com jovens e adultos - que implicações decorrem disso para a organização pedagógica dos processos de ensinar e de aprender, aqui compreendidos como atividade humana, como práxis.

Nos parâmetros da teoria histórico-cultural, a atividade ganha centralidade para a compreensão do desenvolvimento humano, fundamentalmente pelas contribuições de Lev Vigotski e Alexei Leontiev, mas também por seus colaboradores Alexander Luria e Vasili Davidov, entre outros não menos importantes ${ }^{4}$. Com base na categoria de trabalho, atividade vital em Marx, esta escola de psicologia argumenta que sem essa atividade tipicamente humana não teriam se desenvolvido, nos seres humanos, aquelas capacidades, habilidades ou, nos termos vigotskianos, as funções psíquicas características do que chamamos gênero humano, como a linguagem, a abstração, a memória simbólica, a generalização, a atenção voluntária, a imaginação e a criação, entre outras, cuja gênese não se acha nos limites filogenéticos, mas no âmbito das relações sociais, na sociogênese, na prática social com toda a sua complexidade, e na microgênese como coisa para $s i^{5}$, constituindo a subjetividade do indivíduo ${ }^{6}$. Ou seja,

\footnotetext{
${ }^{4}$ Para um melhor conhecimento da Escola de Vigotski, sugerimos a leitura dos três volumes de Ensino Desenvolvimental (PUENTES; LONGAREZI, 2013a; 2017; 2019).

${ }^{5}$ Nesse ponto, recomendamos a leitura de Duarte (2013), sobre a constituição da subjetividade humana. O autor aborda processos de vida cotidiana que reproduzem o gênero humano por meio de objetivações genéricas em si (aprender a falar, a comer, a se relacionar), a partir das quais são produzidas novas e mais complexas formas de se relacionar com a natureza (as objetivações genéricas para si), dentre as quais a ciência, a arte e a filosofia.

${ }^{6}$ Para a teoria histórico-cultural, o desenvolvimento humano é resultado do amálgama de quatro planos genéticos: filogênese, ontogênese, sociogênese, microgênese, sendo que os dois últimos se referem ao que, no humano, não está determinado pela Educação em Revista|Belo Horizonte|v.36|e229610|2020
} 
a atividade está na origem do que em nós é humano e não se reduz à ação mecânica ou motora dos indivíduos. Trata-se de algo um pouco mais complexo. Nestes termos, a natureza humana é uma construção cultural. Não nascemos humanos, nos tornamos humanos pela mediação de artefatos materiais e simbólicos disponíveis na cultura que, por sua vez, são produtos das transformações na natureza decorrentes da ação humana (trabalho), logo, historicamente produzida. O humano, enquanto gênero, não nos é garantido pela natureza biológica que nos constitui espécie. E, como nos lembra Saviani (2013), o que não é garantido pela natureza (biológica), tem de ser, de algum modo, produzido pelos seres humanos. Nesse caso, o ser e o gênero humano igualmente. A esse respeito, Leontiev (2004, p. 285) se pronuncia, afirmando que

Podemos dizer que cada indivíduo aprende a ser um homem. O que a natureza lhe dá quando nasce não lhe basta para viver em sociedade. É-lhe ainda preciso adquirir o que foi alcançado no decurso do desenvolvimento histórico da sociedade humana.

Ancorada no materialismo histórico-dialético, a teoria histórico-cultural de Vigotski e colaboradores pressupõe a natureza histórico-cultural do psiquismo humano como resultado da atividade vital que agrega, por assim dizer, os elementos fundantes do humano, sem os quais não há reprodução e continuidade do gênero humano: o trabalho e a linguagem. Tal como sublinham Marx e Engels, em $A$ Ideologia Alemã (1993), o princípio inicial, primeiro, de toda a história humana é a existência de indivíduos humanos que produzem seus próprios meios de subsistência e, ao fazê-lo, produzem indiretamente a própria vida material. À base das relações que se imbricam nesse processo, emerge a consciência. Sob este prisma, só tem sentido falar do ser humano como relação. Como insiste Marx, na sua sexta tese sobre Feuerbach, "[...] a essência do homem não é uma abstração inerente ao indivíduo isolado. Na sua realidade, ela é o conjunto das relações sociais" (MARX; ENGELS, 1993, p. 13). Logo, a gênese e constituição do que é humano, em cada indivíduo da espécie, encontra-se nos vínculos sociais que estabelece mediado pela produção, pelo ato de trabalhar como ato de criação, de invenção de artefatos mediadores da sua relação com a natureza. Daí que a base da constituição do ser social é o trabalho, compreendido, pois, como atividade vital humana. Vital porque torna-se a atividade por meio da qual se garante a reprodução do humano em cada indivíduo, na qual estão complexamente amalgamadas a linguagem e a consciência.

No que tange ao funcionamento psicológico tipicamente humano - que é, ao fim e ao cabo, o que nos mobiliza aqui, dada nossa preocupação com processos de ensinar e de aprender -, as transformações advindas do invento do trabalho (atividade vital) podem ser notadas nas importantes mudanças ocorridas na anatomia do ser humano, em órgãos físicos como as mãos e as cordas vocais, pela geração de demandas de comunicação e sociabilidade. Essas mudanças são destacadas por Leontiev (2004), no âmbito da psicologia histórico-cultural, ao se referir à influência dos inventos tecnológicos no desenvolvimento do cérebro, órgão biológico do funcionamento psicológico. Nas suas palavras,

Sabe-se que a hominização dos antepassados animais do homem se deve ao aparecimento do
trabalho e, sobre esta base, da sociedade. 'O trabalho, escreve Engels, criou o próprio homem'.
Ele criou também a consciência do homem. O aparecimento e o desenvolvimento do trabalho,
condição primeira e fundamental da existência do homem, acarretam a transformação e a
hominização do cérebro, dos órgãos de atividade externa e dos órgãos dos sentidos. 'Primeiro o
trabalho, escreve Engels, depois dele, e ao mesmo tempo que ele, a linguagem: tais são os dois
estímulos essenciais sob a influência dos quais o cérebro de um macaco se transformou pouco a
pouco num cérebro humano, que mau grado toda a semelhança o supera de longe em tamanho
e em perfeição'. (LEONTIEV, 2004, p. 76).

Notadamente, não é somente a anatomia humana que se modifica pelo trabalho. Na medida em que a atividade com finalidade se assenta na organização coletiva, cooperativa, ela também supõe uma organização deste coletivo, mesmo que inicial e de certo modo precária. Ainda assim, ela funda um

herança biológica, mas pelo que é histórica e culturalmente produto da ação humana. Sugerimos leitura de: Wertsch (1985), Oliveira (1993), Smolka (2001), Vigotski e Luria (1996). 
espaço-tempo em que se estabelecem relações sociais das quais emergem, mais do que capacidades técnicas de realização da vida, laços societários que se constituem berço para a emergência de modos diferenciados de funcionamento psíquico. Como sublinha Leontiev (2004), o trabalho é uma ação sobre a natureza, ligando entre si os participantes, mediatizando a sua comunicação, o que promove, no dizer de Luria (1991), transformações radicais na estrutura do comportamento que passa a apresentar um caráter de complexidade bastante diferente se comparado à herança biológica da espécie. Nasce, pois, com o trabalho coletivo e a linguagem que se estabelece pela necessidade de comunicação, o gênero humano. Nestes termos, o trabalho tem valor ontológico, de criação do Ser que o cria, de estender o alcance dos limites biológicos da espécie na produção de tecnologias e de laços societários.

Trata-se, muito mais, de uma determinada forma de atividade dos indivíduos, determinada forma de manifestar sua vida, determinado modo de vida dos mesmos. Tal como os indivíduos manifestam sua vida, assim são eles. O que eles são coincide, portanto, com sua produção, tanto com o que produzem, como com o modo como produzem. O que os indivíduos são, portanto, depende das condições materiais de sua produção. (MARX; ENGELS, 1993, p. 27, grifos no original).

Eis o valor ontológico do trabalho. Ele é a atividade vital constituidora do humano em cada indivíduo. O humano inventa o trabalho e o trabalho inventa o humano. Não qualquer trabalho, mas o trabalho social ${ }^{7}$, coletivo e criativo, que põe em movimento, no ser humano, o seu órgão biológico mais complexo - o cérebro - e que promove novas e mais sofisticadas conexões, gerando, no homem, a imagem psíquica de si e do mundo físico, habilitando-o à produção de sentidos e significados cada vez mais complexos de sua própria existência.

Alguns elementos importantes, a nosso ver, podem ser elencados aqui para o diálogo com o objeto desta reflexão: $o$ ativo das metodologias ativas. Primeiro: se podemos falar de aprendizagem ativa, é porque concebemos o humano como resultado de atividade. Se assim o é, o humano em cada indivíduo depende dessa atividade. Essa atividade, que é um amálgama entre ação e reflexo psíquico, entre ação e consciência da ação, tem finalidade, tem motivo, mobiliza, no indivíduo, modos de funcionamento psíquico distintos e complexos e, para usar uma expressão vigotskiana, atua na conversão de funções psicológicas elementares (inatas, biológicas, típicas da espécie) em funções psicológicas superiores, cuja gênese está na cultura produzida pelos inventos e relações criadas pelo gênero humano.

Segundo: a atividade realizada na apropriação de artefatos materiais e simbólicos que acontece no processo de conhecimento escolar é um processo de objetivação do gênero humano em cada indivíduo, o que torna a tarefa de ensinar um tanto mais complexa e severa do que simplesmente organizar estratégias consideradas ativas de aprendizagem. Ensinar, nessa perspectiva, requer compreender que ativa é a cognição bumana que, no movimento de tornar próprio um dado conhecimento (cognitivo, procedimental ou atitudinal), torna seu, toma para si, não somente o conceito, mas o modo de operar do pensamento humano objetivado naquele conceito que passa - pela ação intelectual (atividade) de atenção voluntária, abstração, generalização, pensamento teórico etc. - a constituir, de algum modo, subjetivação do próprio indivíduo. Ao fazê-lo, apropria-se de ferramentas intelectuais complexas e, com elas, da complexidade dialética do gênero humano. Esse processo garante ao indivíduo o pertencimento ao gênero humano ao mesmo tempo que o reproduz, recria, reinventa em processos de objetivação e subjetivação permanentes. Daí que a atividade assume centralidade no processo de constituição do humano e da humanidade, medeia a relação entre os seres humanos e o seu entorno social. Esse movimento de apropriação-objetivação-subjetivação se realiza na medida em que, ao agir sobre a realidade, se modificam, se transformam reciprocamente, o objeto e o sujeito da atividade.

Terceiro: o que está em jogo, então, no uso das chamadas metodologias ativas, se as tomamos desde esse referencial, não é apenas o fato de que, por meio delas, ocorrem movimentos físicos

\footnotetext{
${ }^{7} \mathrm{O}$ conceito de trabalho social de Marx tem dois sentidos: um sentido negativo, enquanto atividade alienada e alienante do trabalhador, frente à propriedade privada dos meios de produção; outro sentido decorre da análise filosófica do trabalho bumano que Marx apresenta no capítulo V de O Capital (1996) e que serve de fundamento ao conceito de trabalho considerado, aqui, o modelo para pensar a atividade psíquica humana.
} 
e intelectuais nos que protagonizam o processo de ensino e de aprendizagem. O que está em pauta é que esse movimento coloca coletivos de estudantes e professores para buscar solução a problematizações que se transformam em objeto de investigação, análise, síntese, novas problematizações. O objeto da atividade (de ensino, de aprendizagem, de conhecimento), por sua vez, é um invento humano, da realidade social, cuja apropriação amplifica possibilidades de gênero humano na medida em que, ao apropriar-se da realidade, da prática social inerente ao objeto em estudo, o ser humano a reflete psiquicamente. Leontiev (2004) lembra ainda que, na apropriação de conhecimentos humanos, de cultura produzida historicamente, põem-se em movimento processos de passagem da consciência social para a consciência individual. Logo, numa ação de aprendizagem ativa coletiva, como propõem as diferentes metodologias ativas, o que está em jogo é mais do que motivações ou a superação de teorias tradicionais de ensino. Tais processos põem em movimento os elementos fundantes de objetivação e subjetivação .

Todas as funções psíquicas superiores são relações interiorizadas de ordem social, são o fundamento da estrutura social da personalidade. Sua composição, estrutura genética e modo de ação, em uma palavra, toda sua natureza é social; inclusive ao converter-se em processos psíquicos continua sendo quase social. $\mathrm{O}$ homem, inclusive quando a sós consigo mesmo, conserva funções de comunicação. Modificando a conhecida tese de Marx, poderíamos dizer que a natureza psíquica do homem vem a ser um conjunto de relações sociais transladadas ao interior e convertidas em funções da personalidade e em formas de sua estrutura. Não pretendemos dizer que seja esse, precisamente, o significado da tese de Marx, mas vemos nela a expressão mais completa de todo o resultado da história do desenvolvimento cultural. (VIGOTSKI, 2000, p. 150, tradução nossa).

Toda função superior de pensamento foi, antes de sê-lo, uma relação social. Isto é, a abstração, a generalização, o pensamento teórico, criador, estão antes entre os indivíduos, circulando por entre, nos diálogos, nas argumentações, nas teorizações decorrentes de sucessivas aproximações de objetos de estudo que, por sua vez, objetivam abstrações, linguagem, métodos de desenvolvimento, pensamento humano acumulado na história. Isso tudo constitui o inter que, pela mediação da palavra (dos outros, dos textos, dos hipertextos amalgamados em um dado objeto), converte-se em funções psíquicas tipicamente humanas subjetivadas, internalizadas e em movimento. No desenvolvimento cultural, sublinha Vigotski (2000, p. 150, tradução nossa), “[...] cada função aparece em cena duas vezes, em dois planos, primeiro o social, depois o psicológico. Primeiro entre pessoas como uma categoria interpsicológica, depois no interior [...] como categoria intrapsicológica.”

Quarto: essa atividade de apreensão-apropriação-subjetivação, em que se amplificam, modificam, convertem funções de pensamento teórico, generalizações, criações etc., traduz um movimento cognitivo, uma atividade intelectual, que, por sua vez, demanda, da docência ocupada com a atividade de ensino, clareza do caminho da cognição que apreende o objeto para dar sentido, significado, no contexto no qual se insere o objeto de estudo. Isso implica método, ou seja, compreensão e organização de um caminho, de uma lógica que gera, no indivíduo - síntese de relações sociais -, um percurso intelectual de apreensão de um dado objeto de conhecimento.

Sob este prisma, a estratégia ativa de aprendizagem não se reduz ao movimento físico ou meramente empírico dos que a protagonizam. É, antes de tudo, o que põe em movimento o pensamento complexo, o que pode se realizar por ações coletivas (problematizações, debates, diálogos, estratégias de seminário etc.) e por ações individuais de estudo (leitura e apreensão de modos de pensamento contidos no objeto: conceitos, categorias etc.), prenhes de vozes, valores, prática social, objetivadas num texto cuja análise esteja respondendo a necessidades e motivos geradores da atividade. Notadamente, a categoria de atividade vital (trabalho), como ação coletiva que desencadeia em cada indivíduo processos complexos de cognição e personalidade, carrega em si um importante componente pedagógico: é o coletivo, mediado pela necessidade de resolução de problemas, que suscita a atividade de pensar. Contudo, o coletivo é mais do que o trabalho em grupo. O coletivo também é o conjunto das objetivações humanas contidas nas invenções tecnológicas, no conhecimento produzido na ciência, na arte, na filosofia. $\mathrm{O}$

\footnotetext{
${ }^{8}$ Sobre processos de objetivação e subjetivação, recomendamos a leitura de Newton Duarte (2013).
} Educação em Revista|Belo Horizonte|v.36|e229610|2020 
coletivo é o conjunto de relações sociais inerentes a cada indivíduo que dialoga a vida a partir do lugar social que ocupa no conjunto de tais relações. Isso quer dizer que, quando colocamos estudantes para resolver problemas, estamos tratando de sujeitos humanos concretos cujas subjetividades são sínteses de práticas sociais vividas, nas quais se constituem subjetivamente. Não são, pois, sujeitos empíricos. São seres humanos, humanizados nas possibilidades e circunstâncias históricas nas quais se encontram. Sair dessa condição para outros formatos de subjetivação - o que requer a mediação das objetivações humanas para si que estão não só, mas em grande medida, no conhecimento historicamente produzido e acumulado que tem lugar na educação escolar e na educação superior - ganha contornos ainda mais severos. Daí que a busca de soluções de problematizações, se quiser desenvolver o humano, não pode prescindir do conhecimento clássico, da apreensão de categorias teóricas fundamentais nos diferentes campos do saber humano.

Trata-se de perceber que, ao fim e ao cabo, a ação de instrução, coletiva ou individual, que busca a resolução de problemas, somada ao conhecimento historicamente produzido, medeia processos de constituição da personalidade. Isso, de acordo com a Escola de Vigotski, só é possível mediante a atividade do ser humano com outros seres humanos e a humanidade inerente às suas invenções e criações acumuladas na história. Tomar esse conceito como fundante da organização de processos de ensino e de aprendizagem no âmbito da educação superior é nossa intenção para a próxima seção desse texto.

\section{ATIVIDADE DE ENSINO-APRENDIZAGEM COMO FATOR DE DESENVOLVIMENTO HUMANO NO CONTEXTO DA EDUCAÇÃO SUPERIOR}

O que é a atividade? Como se constitui em elemento fundamental de desenvolvimento humano? $\mathrm{O}$ que esse conceito sugere para a organização pedagógica de processos de ensinar e de aprender no âmbito da educação superior? Iniciamos possíveis reflexões sobre essas questões, concordando com Puentes e Longarezi (2013b, p. 264), ao definirem a atividade, com base em Leontiev, como "[...] processo no qual a realidade é transformada pelos esforços criativos dos homens e no qual o trabalho é a forma original dessa transformação.” Dialogando com Talizina, os autores também afirmam que o desenvolvimento humano

[...] se caracteriza, antes que nada, pelas formações novas, isto é, pelas mudanças qualitativas na vida psíquica do homem [...]. O desenvolvimento intelectual [especificamente] se dá em consonância com duas linhas: 1) o desenvolvimento funcional do intelecto, que consiste no enriquecimento do conteúdo por intermédio das ações intelectuais e conceitos novos; 2) o desenvolvimento por estágios (por idade) que se caracteriza pelas mudanças qualitativas no intelecto e sua reestruturação [...]. É importante afirmar que as duas linhas indicadas do desenvolvimento intelectual se inter-relacionam [...]. (TALIZINA, 2000, p. 305 apud PUENTES; LONGAREZI, 2013b, p. 252).

Para Leontiev (2010), cada etapa do desenvolvimento humano é regida, por assim dizer, por uma atividade principal, uma atividade guia que, em sendo principal, não significa que seja a única, senão que é a dominante de um dado período. Trata-se, de acordo com a teoria histórico-cultural, da atividade que caracteriza um tempo histórico e, portanto, social, do desenvolvimento humano. É o modo como se dá a relação do indivíduo com seu entorno social e cultural.

De acordo com Facci (2004), ao estudar a periodização do desenvolvimento humano a partir de Leontiev, Elkonin e Vigotski, resumidamente, temos atividades principais ou atividades guias desde o nascimento à vida adulta: i) nos bebês, a comunicação emocional direta com os adultos próximos; ii) na primeira infância, a atividade objetal-instrumental; iii) no período pré-escolar, a brincadeira e o jogo simbólico; iv) na fase escolar, o estudo - cabendo à escola a tarefa de desenvolvimento do pensamento teórico por meio da apropriação do conhecimento, das formas de produção do conhecimento, seus conceitos e processos; v) na adolescência, a comunicação íntima pessoal - atividade por meio da qual se modificam as relações com o universo social e cultural e ampliam-se as dimensões éticas e estéticas da vida, salientando-se que a atividade de estudo segue sendo importante, já que há, também, maior domínio de tal atividade, do pensamento conceitual, da estrutura (método) da atividade, assim como formação do 
caráter voluntário e, portanto, maior domínio volitivo-afetivo, tomada de consciência de si e dos demais etc.; vi) na adolescência final e vida adulta, a atividade profissional de estudo ou atividade trabalho/estudo - fruto de avanços intelectuais importantes já da fase anterior, como o pensamento abstrato, operação por conceitos ou categorias teóricas, cujo conteúdo passa, agora, a orientar ações concretas da vida e para a atuação profissional.

A transição de um estágio de desenvolvimento para o outro muda o tipo de atividade principal na relação dominante do indivíduo com a realidade. Ela é, assim, aquela atividade marcante dentro da qual surgem outros tipos de atividade. Por meio dela, processos psíquicos particulares tomam forma ou são reorganizados, como no caso da brincadeira, em que funções como imaginação e criação são inicialmente moldadas no brinquedo, e os processos de abstração e generalização, quando a atividade principal passa a ser o estudo. Enfim, como sublinha Leontiev (2010), a atividade principal ou guia é aquela da qual dependem de forma íntima as principais mudanças psicológicas na personalidade, observadas em um certo período do desenvolvimento (infância, adolescência, fase adulta, velhice). É a atividade que guia o desenvolvimento, "[...] em conexão com a qual ocorrem as mais importantes mudanças no desenvolvimento psíquico." (LEONTIEV, 2010, p. 122). Por meio da atividade principal, $\mathrm{o}$ indivíduo se relaciona com seu entorno social, incorporando às suas atividades sistemas de instrumentos psicológicos disponíveis na cultura, o que gera desenvolvimento psíquico e o equipa para a vida.

Para os fins de nossa reflexão, tomamos aqui a atividade trabalho/estudo como referência para pensar a atividade de ensino e a atividade de aprendizagem no contexto temporal de desenvolvimento humano compreendido entre a juventude e a vida adulta. Em acordo com Abrantes e Bulhões (2016), tomaremos essas etapas da vida como etapas de desenvolvimento psíquico que, no âmbito da teoria histórico-cultural, resultam da unidade dialética entre aspectos objetivos e subjetivos, não se separando, portanto, o psíquico dos processos sociais, que são, no caso de funções superiores de pensamento, seu lugar de origem. Partimos do pressuposto que

[...] a juventude entendida como fase adulta inicial apresenta uma relação com a atividade de formação profissional (ou conformação), independentemente se esse processo ocorre no trabalho ou nas instituições educativas, o que depende da situação concreta do jovem. Nesse sentido, mais determinante que a idade para compreender a atividade do jovem perante o mundo e suas possibilidades de desenvolver-se é sua relação com o trabalho, ou seja, sua luta por autonomia e pela possibilidade de realização de uma atividade socialmente produtiva. (ABRANTES; BULHÕES, 2016, p. 247).

Daí que, ainda dialogando com as reflexões dos autores supracitados, a atividade principal desse tempo histórico de desenvolvimento possa ser nominada como atividade trabalho/estudo e siga os mesmos princípios das demais fases da vida, caracterizando-se como traço principal da atividade humana jovem e adulta, processo mediador da relação entre os indivíduos (jovens e adultos) e as objetivações humanas inerentes aos objetos e diferentes processos dos quais fazem parte. Lugar onde se põem em movimento, se originam e desenvolvem funções superiores de pensamento, dado que cada etapa de desenvolvimento humano está sendo delimitada, conceituada e mediada por conteúdos sociais historicamente produzidos e de cuja transmissão dependem os processos de humanização desejados como tarefa última da educação. Como afirma Leontiev (2010, p. 65),

O caso é que cada nova geração e cada novo indivíduo pertencente a uma certa geração possuem certas condições já dadas na vida, que produzem também o conteúdo de sua atividade possível, qualquer que seja ela. Por isso, embora notemos um certo caráter periódico no desenvolvimento da psiquê [..], o conteúdo dos estágios, entretanto, não é, de forma alguma, independente das condições concretas nas quais ocorre o desenvolvimento. É dessas condições que esse conteúdo depende primeiramente.

Há, aí, um princípio pedagógico fundamental para a atividade de ensino como atividade do professor. O que o indivíduo é, é o que ele está sendo neste tempo histórico. Ou seja, esse indivíduo no nosso caso, no tempo da atividade trabalho/estudo - é um indivíduo situado socialmente. Ele ocupa 
um lugar social que incide sobre seu desenvolvimento, na medida em que delimita suas condições de apropriação e subjetivação como gênero humano. Neste sentido, o jovem ou o adulto, estudante universitário, não se reduz ao seu tempo cronológico ou biológico. O que, de fato, é determinante para compreender os modos de ser de jovens e adultos são as condições reais em que se acham e se fazem as suas relações de trabalho e produção.

Assim, no âmbito da pedagogia universitária voltada para o desenvolvimento humano do tempo histórico da juventude e da vida adulta, analisar o desenvolvimento e identificar a atividade guia (estudo-trabalho-profissão), de modo a direcionar a ação educativa para a práxis consciente, implica "[...] pressupor a unidade contraditória entre a atividade de estudo profissionalizante e a atividade produtiva, destacando que a predominância de uma delas ocorre pela determinação da posição que o jovem ocupa em relação aos meios de produção." (ABRANTES; BULHÕES, 2016, p. 242, grifos no original). Quem é o jovem, o adulto que, nos bancos universitários, assume a atividade de estudo? Como se relaciona com o mundo do trabalho? E o que é ou como está sendo o mundo do trabalho para ele? Que lugares sociais constituem a trama de relações em que se encontra imerso? Que tempo histórico é esse? Que características têm assumido o modelo de produção, as relações de trabalho e produção ordenadas neste modelo? Que valores, ideias, modos de funcionamento humano essas relações têm objetivado? Se é a existência que determina a essência humana (MARX; ENGELS, 1993), como têm se produzido subjetividades jovens e adultas nessa complexidade do trabalho (atividade vital do gênero humano) que produz e modifica as formas de relação do ser humano com o seu meio, produzindo cultura? Daí que considerar esse lugar social de onde vêm os estudantes constitua tarefa primordial da docência para compreender a constituição do pensamento, o domínio psíquico da realidade que possuem os estudantes e que foi (está sendo) produzido na sua prática social. Aí residem e se constituem os conteúdos do seu modo de pensar, de ser, de interpretar a vida, de refletir psiquicamente a realidade, e que, em termos pedagógicos e metodológicos, constituem pontos de partida e de chegada do processo de conhecimento escolar no âmbito da atividade principal trabalho/estudo.

Ao explicar o conceito de atividade principal, Leontiev (2010) sublinha que tal atividade se estrutura por componentes centrais, que são: necessidades, motivos, metas, condições, meios, ações e operações. As necessidades e os motivos constituem as condições primeiras da atividade e precisam estar, de certo modo, articulados para que uma atividade de aprendizagem ou de ensino aconteça. A atividade, insiste o autor, tem como condição primeira a necessidade e pressupõe a coincidência entre o motivo da ação e seu objetivo. Exemplifica sua tese, dando prosseguimento à argumentação, ao dizer:

Exemplifiquemos isso por um exemplo. Admitamos que um estudante, preparando-se para um exame, leia um livro de história. Será este, psicologicamente, um processo tal que possamos adequadamente chamá-lo de atividade, nos termos em que acabamos de acordar? Não podemos dizer imediatamente, porque o caráter psicológico do processo exige saber o que ele representa para o próprio sujeito. E, para tanto, precisamos de uma análise psicológica do próprio processo. Admitamos que um colega de nosso estudante lhe diga que o livro que está lendo não é absolutamente necessário para o exame. Poderá então ocorrer o seguinte: o estudante poderá imediatamente pôr o livro de lado, poderá continuar sua leitura ou talvez desistir da leitura com relutância, com pena. Nos dois últimos casos, é óbvio que aquilo que dirigiu o processo de leitura, isto é, o conteúdo do livro, estimulou por si mesmo o processo, em outras palavras, o conteúdo do livro foi o motivo. [...] alguma necessidade especial do estudante obteve satisfação no domínio do conteúdo do livro - uma necessidade de conhecer, de entender, de compreender aquilo que tratava o livro. O primeiro caso é diferente. [...] ao saber que o conteúdo do livro não estava no roteiro do teste, prontamente abandou a leitura, fica claro que o motivo que o levou a ler o livro não era o conteúdo do livro por si mesmo, mas apenas a necessidade de ser aprovado no exame. Aquilo para o qual sua leitura se dirigia não coincidia com aquilo que o induzia a ler. Nesse caso, por conseguinte, a leitura não era propriamente uma atividade. A atividade, neste caso, era a preparação para o exame, e não a leitura do livro por si mesmo. (LEONTIEV, 2010, p. 68).

Embora longo, esse excerto nos ajuda a refletir sobre os sentidos de uma atividade de ensino e de aprendizagem, especialmente no que se refere ao trabalho intencional da docência, sua didática atenta aos processos de desenvolvimento humano. O exemplo de Leontiev permite inferir que a ação dirigida, objetivada do ensino, orientada por metodologias ou estratégias de condução do pensamento 
abstrato ao concreto, produz a necessidade, gera o motivo da atividade de aprendizagem e organiza as ações e operações necessárias à realização de tal atividade. O que motiva à aprendizagem, pois, não é somente uma estratégia de aprendizagem ativa que coloque os sujeitos para se encontrarem e realizarem ações conjuntas. O que motiva, o que gera a necessidade, está ligado a processos de problematização que se fazem na articulação entre a prática social dos indivíduos e o conhecimento historicamente acumulado. Adverte-se, pois, que para compreender o processo intelectual, os formatos cognitivos dos estudantes, é necessário partir de sua atividade de vida real, de sua prática social. Daí que, conforme propõem Longarezi e Franco (2013), a ação educativa do processo de ensino (atividade de ensino), docência, deva, necessariamente, prestar atenção para que sua atividade de ensino se converta em atividade de aprendizagem, ou seja, se constitua em atividade para o estudante. Nas palavras dos autores,

[...] para que a atividade do professor se constitua em atividade do estudante é necessário que ela parta da identificação das necessidades preliminares dos estudantes, tendo em vista a construção de necessidades coletivas, primeira condição de toda e qualquer atividade. Nesse processo, demanda ainda educar os motivos para que os motivos-estímulos se transformem em motivos formadores de sentido, fazendo com que o que move os sujeitos no contexto escolar coincida com o objeto a que essas ações se dirigem. (LONGAREZI; FRANCO, 2013, p. 96).

A gênese das necessidades e dos motivos, componentes estruturantes da atividade de aprendizagem, encontra-se nos contextos históricos, nas complexas redes sociais, nas práticas sociais (que são também modos de representação psíquica da realidade) dos indivíduos, e estão em movimento, isto é, o que hoje é de um jeito feito de jeitos anteriores, amanhã poderá apresentar outras características, dado que, desde os primórdios humanos, experimentamos transformações permanentes decorrentes da ação criadora do ser humano.

No sentido aqui assumido, pois, o ensino não se fragmenta ou se dilui no interesse individual (individualizante), apenas, mas centra-se na organização e construção coletiva de necessidades e motivos que medeiem o desenvolvimento do gênero humano em cada um, o que, no âmbito da educação superior (mas não só), implica: de um lado, o domínio dos conhecimentos culturais, conceitos, categorias teóricas, elementos centrais que agregam, objetivam o pensamento humano numa dada área de conhecimento e, de outro, a organização de estratégias (didática) por meio das quais tais conceitos, categorias, pensamentos, sejam apropriados e subjetivados. Ademais, implica compreender como os processos psíquicos se organizam e encontram razões de ser de um dado conteúdo ou conhecimento. Isso significa, na perspectiva histórico-cultural, o reconhecimento de que o pensamento teórico (tarefa primordial da educação escolar) se desenvolve na articulação entre prática social e conhecimento acumulado pelos seres humanos ao longo da história.

\footnotetext{
Assim, no contexto do processo educativo, as atividades de ensino e de aprendizagem precisam estar articuladas por uma necessidade comum, enquanto o motivo dessas ações (aquilo que move os sujeitos nesse processo) precisa coincidir com suas finalidades. A atividade consiste, portanto, num conjunto de ações articuladas entre si por objetivos comuns que potencializam o desenvolvimento da psique e da personalidade humana, isto é, o desenvolvimento integral do homem. (PUENTES; LONGAREZI, 2013b, p. 264).
}

Sob este prisma, a função precípua da educação escolar, compreendida como percurso formativo que vai da tenra infância à educação superior, é, em última análise, o desenvolvimento em cada indivíduo daquilo que constitui o gênero humano, de modo a garantir sua produção e reprodução. Nestes termos, concordamos com Saviani (2013, p. 13, grifos nossos), quando o autor define que,

[...] o trabalho educativo é o ato de produzir, direta e intencionalmente, em cada individuo singular, a bumanidade que é produzida bistórica e coletivamente pelo conjunto dos homens. Assim, o objeto da educação diz respeito, de um lado, à identificação dos elementos culturais que precisam ser assimilados pelos indivíduos da espécie humana para que eles se tornem humanos e, de outro lado e concomitantemente, à descoberta das formas mais adequadas para atingir esse objetivo. 
Se o trabalho educativo é o ato intencional de produção da humanidade em cada indivíduo, depreende-se que a ação do professor ou da professora (que executa o trabalho educativo por meio da ação da docência) é uma ação objetivada, planejada, voltada para a promoção de uma humanidade que, como bem lembra o autor citado, é uma humanidade historicamente produzida. Isso, por sua vez, requer que, na intenção da docência, se mostrem tanto os elementos culturais (conhecimentos, conceitos, procedimentos, ética e estética) quanto os meios pelos quais o ensino desempenhará a tarefa de humanização (formas mais adequadas de atingir esse objetivo). Esse processo faz do professor e da professora algo mais do que facilitadores, já que demanda uma ação pedagógica pensada, que articule os conhecimentos, conceitos, categorias teóricas da área de conhecimento na qual atua com os procedimentos metodológicos que objetivam a organização de caminhos cognitivos praxiológicos para a apreensão do objeto de estudo, ao mesmo tempo que medeie, em cada indivíduo, o desenvolvimento de funções de pensamento complexo, não como aprendizagem fictícia, mas como modo fundamental de contribuir para a reprodução do gênero humano.

Cabe à práxis a tarefa de orientar o pensamento. O sentido da análise se efetiva por um conjunto de ações e operações intelectuais mediadas pelos conteúdos em diálogo com a prática social. Logo, a atividade de análise que se faz pela atividade trabalho/estudo parte da percepção imediata, sincrética, caótica, da realidade tal como ela se apresenta. Penetra, em seguida, por meio da instrumentalização de conhecimentos, em abstrações e conceitos, reconstruindo o processo histórico de constituição dessa realidade, retornando ao ponto de partida que, agora, visto desse movimento do pensamento na direção de apreendê-lo, deixa de ser o incompreendido da percepção imediata para constituir-se, conceitualmente, numa totalidade ricamente articulada. É esse movimento cognitivo, esse percurso do pensamento da síncrese à síntese, que traduz o método ativo de apreender, objetivar e subjetivar-se no e pelo processo de ensino. Há que se penetrar, fazer um detóur, como nos orienta Kosik (1976), na história do objeto da atividade de ensino-aprendizagem, ele mesmo marcado pelas pegadas que a humanidade vai deixando em seus atos, criações, produções que objetivam o pensamento (fórmulas, conceitos, categorias lógicas, compreensões, desejos, valores, necessidades, teses, antíteses, sínteses). Por esse movimento de práxis vai se constituindo o pensamento teórico, antes caótico, sincrético, difuso. Agora, sintético, objetivado no concreto pensado, para ser novamente desafiado numa sucessiva e infinita rede de cognição que tece, em cada indivíduo, a humanidade.

Compreender a realidade significa, então, passar de uma representação difusa, caótica, a uma concepção concreta, o que implica, necessariamente, a assimilação de saberes e modos de pensamento objetivados nesses saberes transmitidos de geração em geração. O pensamento, num movimento espiral de idas e vindas ao objeto (ponto de partida e de chegada), chega a conteúdos desconhecidos no ponto de partida. E aí se explicitam interpretações novas do objeto da atividade de estudo e possibilidades de transformação que se vão efetivando no desenvolvimento da ciência, da tecnologia, da arte, enfim, das criações do gênero humano.

Cada geração começa, portanto, a sua vida num mundo de objetos e de fenômenos criados pelas
gerações precedentes. Ela apropria-se das riquezas deste mundo participando no trabalho, na
produção e nas diversas formas de atividade social e desenvolvendo assim as aptidões
especificamente humanas que se cristalizaram, encarnaram nesse mundo. Com efeito, mesmo a
aptidão para usar a linguagem articulada só se forma em cada geração, pela aprendizagem da
língua que se desenvolveu num processo histórico, em função das características objetivas desta
língua. O mesmo se passa com o desenvolvimento do pensamento ou da aquisição do saber. Está fora de questão
que a experiência individual do homem, por mais rica que seja, baste para produzir a formação de um pensamento
lógico ou matemático abstrato e sistemas conceituais correspondentes. [...]. De fato, o mesmo pensamento e o saber
de uma geração formam-se a partir da apropriação dos resultados da atividade cognitiva das geraçóes precedentes.
(LEONTIEV, 2004, p. 284, grifos nossos).

Chamamos atenção, no excerto apresentado, para o argumento do autor de que o pensamento e o saber de uma geração só se formam pela apropriação dos resultados da atividade cognitiva das gerações precedentes, sinalizando, a nosso ver, que, apreender um conteúdo, inerente a um campo de conhecimento, implica apropriar-se dos percursos, dos caminhos intelectuais realizados na sua produção, das relações, dos motivos, da inteligência humana objetivada nele. É por isso que, no âmbito 
desta concepção, não se separam teoria e prática e não se ignora a transmissão do conhecimento como tarefa primeira da educação escolar, dado que a atividade cognitiva das gerações precedentes constitui a prática social de seres humanos historicamente situados. Sob este ponto de vista, podemos falar de uma necessária transmissão de conhecimentos que se efetiva tanto pela ação intencional da docência quanto pelas mediações simbólicas e materiais de gerações precedentes contidas nos objetos de estudo. Um livro ou autor clássico estudado transmite elementos fundamentais para a análise de situações reais problematizadas. Uma aula expositiva-dialogada, dirigida para a operação por conceitos, medeia, no estudante, possibilidades de operar intelectualmente uma dada situação e, com essa instrumentalização, equipar-se para criar saídas importantes no âmbito de sua profissão e de sua prática social. Nesse sentido, a leitura silenciosa orientada para um objetivo, como atividade de estudo, é uma metodologia ativa. A exposição-dialogada problematizadora, que se faz pelo movimento de teorização (operação por conceitos) e interpretação de elementos da prática social (ponto de partida e de chegada), é metodologia ativa. Essas são ações que põem em movimento, no indivíduo, possibilidades de operação cognitiva, ensinando modos de operar intelectualmente com a prática social, de subjetivar-se pelas objetivações humanas contidas nos objetos de estudo e de transformar-se em pessoa criadora, inventora e crítica. Esse processo medeia a passagem do pensamento difuso, abstrato, para o concreto. Nessa perspectiva, o que é ativo numa metodologia é o movimento que o pensamento faz na apreensão de um dado objeto de conhecimento.

Explicita-se, pois, a severidade da atividade de ensino e da atividade de aprendizagem, dois processos distintos, mas interdependentes e teleologicamente articulados com fins à humanidade em cada indivíduo. A atividade trabalho/estudo, que é o tempo histórico de desenvolvimento humano tomado como referência desta reflexão, é trabalho criativo que se estrutura com base na apropriação das invenções humanas objetivadas na filosofia, na ciência, na arte etc., que são práxis humanas, e na dialogicidade que se efetiva entre os sujeitos com a história de um dado objeto e consigo mesmo, mediatizados pelas complexas relações sociais contidas no objeto. Ao tomarem esse conteúdo como signo mediador de compreensões e o articularem com as demandas especificas de um dado objeto (realidade, prática social), os sujeitos amplificam as possibilidades de imaginação e criação de novos conhecimentos sobre o objeto, o que confere, a cada um e a cada uma, mais autonomia, liberdade e criticidade no exercício de intervenção pensada, consciente, praxiológica.

Depreende-se, então, que o ensino superior constitui lugar privilegiado para tal feito. Atuando intencionalmente focado no desenvolvimento humano fomentado pela atividade cognoscitiva, investigativa e criadora, o ensino superior promove o aprimoramento do pensamento teórico, autônomo, inquiridor e transformador, constituindo-se espaço-tempo de desenvolvimento de funções superiores de pensamento e contribuindo para o aprimoramento do próprio gênero humano. Neste sentido, o trabalho pedagógico com jovens e adultos, no âmbito da educação superior, implica o reconhecimento do inacabamento dos sujeitos (FREIRE, 1987; 1996), da sua condição de seres históricos, seres de práxis, vivendo um percurso do seu desenvolvimento cuja atividade predominante está situada no âmbito do estudo e do trabalho. E é na articulação desses elementos que se aprofundam e se ampliam, nos sujeitos, as características do gênero humano. Ao fazê-lo, se apropriam da humanidade e a constituem. Considerar esses aspectos do humano, a nosso ver, muda substancialmente o conceito de ativo inerente às metodologias ativas, ao mesmo tempo que nos ajuda a compreender que a atividade acontece também na introspecção, no silêncio de um cérebro tumultuado pelo caos da perguntação, da investigação, pelo barulho de um conteúdo problematizador de objetos de aprendizagem, pela produção de sínteses implicadas num percurso cognitivo - individual enquanto exercício de pensamento conceitual ou categorial, coletivo porque feito de diálogos com autores, colegas, situações de prática social - e pelas circunstâncias sociais e históricas herdadas, pelo lugar social ocupado pelo indivíduo, e plural na diversidade de cores, vozes e significações sociais e culturais que o objetivam. Ativo, então, é o indivíduo que, por sua vez, é, ele mesmo, síntese de múltiplas relações sociais subjetivadas pelas apropriações feitas na mediação do lugar social que ocupa, ou, para usar uma categoria vigotskiana, pela situação social de desenvolvimento.

Nada disso, no entanto, esfumaça ou dilui o papel do professor e da professora, a quem cabe a tarefa rigorosa da mediação pedagógica, que significa ter em mente que sua função primeira é o 
desenvolvimento do pensamento teórico, que é um tipo específico de pensamento superior que só acontece por ocasião da organização pedagógica escolar do conhecimento, dadas suas características e especificidades. Trata-se de um pensamento que se organiza e se efetiva pela mediação de conceitos científicos, de categorias teóricas, de articulação de ações psicológicas que entrecruzam processos de abstração, generalização, atenção e memória lógica, que, em última instância, tomam a realidade para suspendê-la, ad-mirá-la, diria Freire (1987), no sentido de sair dela para vê-la desde outro lugar - processo que, dessa perspectiva, implica a construção de imagem psíquica do objeto em relação com a experiência social.

Assim, mediar atividades de aprendizagem requer uma práxis específica para a atividade de ensino. Caberá à docência esse cuidado da ação pedagógica. Como atividade de ensino geradora de atividade de aprendizagem, não prescinde de ser, ela própria, orientada por necessidades, motivos, ações e operações que coadunem com os motivos ou necessidades dos estudantes.

\section{SÍNTESES POSSÍVEIS PARA EFEITOS DE UMA (IN) CONCLUSÃO}

A reflexão empreendida neste texto é resultado da verticalização de estudos teóricos como parte de um trabalho de investigação que vem se ocupando de construir uma base teórica históricocultural para as metodologias ativas no campo do ensino superior em saúde. Esse movimento pretende fazer frente a uma tendência recente de incorporação tecnicista e acrítica dessas metodologias, particularmente na área da saúde - mas não só -, sob a égide da inovação pedagógica. Resulta daí que, neste texto, trabalhamos com a construção de uma reflexão teórica que aponta um conjunto de categorias prévias mediadoras para outras análises possíveis, incluindo as de dados empíricos. Nestes termos, revisar a teoria e estabelecer possíveis categorias de análise constitui um exercício de pesquisa e produção de conhecimento, a nosso juízo, fundamental quando se trata de uma aproximação ou de diálogos inéditos, como parece ser o caso, aqui. Esse exercício de revisão e aprofundamento de estudos no âmbito da teoria histórico-cultural e, de modo especial, da teoria da atividade, nos possibilita evidenciar alguns elementos importantes para o objeto do qual nos ocupamos e que servirão de basiladores para outras análises sobre o tema em tela. Afinal, que contribuições a teoria histórico-cultural pode oferecer para pensar e propor metodologias ativas no âmbito do ensino superior em saúde? Nos ajuda a compreender o que é o ativo das metodologias ativas? Pode constituir-se em base teórica forte para sustentar estratégias pedagógicas voltadas ao desenvolvimento do pensamento teórico, tipicamente humano?

Notadamente, as reflexões contidas no esforço de teorização deste texto não dão conta da complexidade das respostas exigidas. Por isto, reafirmamos que ele é um empreendimento inicial de busca de um aporte teórico - filosófico, psicológico, pedagógico - para sustentar e mediar análises de dados empíricos, mas também, e principalmente, para encorpar a ação docente no uso e desenvolvimento de estratégias metodológicas ativas, considerando o sentido da atividade de ensino e da atividade de aprendizagem sob o enfoque histórico-cultural da atividade humana. A esse respeito, ponderamos que a teoria histórico-cultural oferece o aporte adequado, visto que, embora ainda sejam necessários aprofundamentos reflexivos nesta direção, alguns elementos já se mostram bastante profícuos para este fim, neles residindo, a nosso juízo, a mais importante contribuição deste texto.

O primeiro desses elementos se refere à concepção de desenvolvimento humano. Por meio do trabalho (atividade vital), o ser humano cria instrumentos de atuação no mundo que, por sua vez, ao modificarem o mundo pela ação humana, promovem mudanças substanciais no humano. Criar instrumentos de trabalho e atuar na transformação do mundo com tais instrumentos, e de modo coletivo, são sinais de capacidades psíquicas e de um tipo de atividade cognitiva muito diferentes das de outras espécies. Além disso, a ação coletiva dos humanos gerou a necessidade de comunicar, donde nasce a linguagem que, por sua vez, implicará um salto qualitativo na divisão das águas da natureza e da cultura na constituição do humano. Por meio da palavra, a subjetividade humana passa a ser objetivada nas suas criações. E a objetivação de suas criações (instrumentos, tecnologias, símbolos, signos), pela mediação social, passa a ser subjetivada nos seres humanos, complexificando a teia de relações que, constituídas de nós, nos constituem como gênero humano. O homem, afirma Leontiev (2004, p. 279, grifos no original), 
"[...] é um ser de natureza social, que tudo o que tem de humano nele provém de sua vida em sociedade, no seio da cultura criada pela humanidade." Assim, quando falamos de desenvolvimento humano, nos referimos àquilo que, em nós, é conquista, é apropriação cultural realizada nas circunstâncias históricas e sociais nas quais estamos imersos e em relação, e cuja gênese e desenvolvimento - nos responde a teoria histórico-cultural - está no trabalho, atividade vital do ser humano, e na linguagem, como elemento mediador e constituidor do humano pelos processos de comunicação e generalização.

$\mathrm{Na}$ esteira da concepção de que o humano é resultado da vida em sociedade, das mediações da cultura produzida nas relações de trabalho, organização e comunicação social (trabalho e linguagem), destaca-se um segundo elemento: a educação escolar como tempo-espaço de encontro dos feitos históricos da humanidade (conhecimento) com as gerações mais jovens, que se humanizam pela mediação desse conhecimento compreendido como objetivação do gênero humano. Isso é a escola, designada pela humanidade como lugar de ensinar e de aprender, de apropriar os artefatos simbólicos (conhecimento), os inventos humanos, que são, em si, objetivações mediadoras de subjetivações, uma vez que, pelo processo pedagógico, dialético e intencional da educação escolar, transferem para os indivíduos os conhecimentos historicamente produzidos, que são invenções do gênero humano. Seja educação básica ou superior, esse é o fim último da educação escolar. Esta severidade do papel da educação escolar para a teoria histórico-cultural coloca o trabalho docente em outro patamar. E esse é um terceiro elemento que queremos destacar. Mais do que alguém que repassa conteúdos com dinâmicas interessantes e consideradas motivadoras do interesse dos estudantes, espera-se do professor, aqui, uma docência que assuma a lógica de um trabalho criador, de uma atividade humana cuja tarefa é o desenvolvimento da própria humanidade, isto é, do gênero humano, em cada indivíduo.

Outro elemento que merece atenção é a centralidade do processo pedagógico no conhecimento e no projeto social de desenvolvimento humano mais amplo. Não é o aluno, não é o professor ou a professora que centraliza. O que centraliza é o conhecimento historicamente produzido, que contém em si as marcas do humano e de cuja apropriação depende o desenvolvimento do humano em cada indivíduo. É o conhecimento clássico, no sentido dado por Saviani (2013), como elemento que objetiva a inteligência humana, as formas complexas de pensamento desenvolvidas pela humanidade ao longo da história, as funções superiores de pensamento (abstração, generalização, criação, imaginação, linguagem etc.), que serão, pela mediação da atividade de ensino, transferidas para os sujeitos em atividade de aprendizagem. Logo, o sujeito que aprende e que ensina não é um humano empírico, mas um humano concreto, histórico, cultural, produto de sínteses da atividade vital do gênero humano que, pela mediação dessas sínteses, objetiva-se como parte ativa desse gênero, transformando-se, pela atividade, em criador do mesmo gênero, que se vai complexificando neste movimento.

Da centralidade no conhecimento clássico, a ser transferido na relação atividade de ensinoatividade de aprendizagem, decorre um outro elemento que cabe destacar: trata-se da dimensão metodológica. Um olhar desatento ou focado em outras concepções de educação pode acusar a teoria histórico-cultural de assumir um perfil autoritário, contrário à ideia de construção do conhecimento tão em voga atualmente, porque faz uso da expressão transmissão do conhecimento. Embora extrapole os limites desta reflexão, importa, aqui, sinalizar que, para a teoria histórico-cultural, a transmissão dos inventos humanos é condição de humanidade. Novamente, nos valemos de Luria (1991), que, ao argumentar sobre a atividade consciente no ser humano, afirma que a transmissão e a informação, que se realizam pela linguagem - comunicação e generalização -, constituem uma forma fundamental de apropriação e desenvolvimento humano e fazem da linguagem o veículo fundamental desse movimento. Notadamente, não se trata de uma transmissão mecânica, feita a partir de uma relação pedagógica autoritária, mas de uma transmissão que gera os elementos teóricos fundamentais de um dado objeto para mediar processos cognitivos de problematização, comparação, cotejamento, produção de hipóteses, afirmação, negação, sínteses que abrigam novas formulações do conhecimento. Isto é o que acontece quando se garante que o caminho (método) de formação do pensamento analítico (teórico, conceitual, categorial, superior) tome a prática social dos seres humanos historicamente situados como ponto de partida e de chegada do conhecimento. Nesse movimento de problematização da prática social (da vida mesma, em sua complexidade), o cotejamento entre o conhecimento histórico, clássico - transmitido pela educação escolar por meio da ciência, da arte, da filosofia -, e as condições concretas de existência 
do humano é o que faz instalar tanto a atividade de ensinar quanto a de aprender. A isso estamos nominando de ativo das metodologias ativas.

\section{REFERÊNCIAS}

ABRANTES, Angelo Antonio; BULHÕES, Larissa. Idade adulta e o desenvolvimento psíquico na sociedade de classes. In: MARTINS, Ligia Márcia; ABRANTES, Angelo Antonio; FACCI, Marilda Gonçalves Dias. Periodização histórico-cultural do desenvolvimento psíquico: do nascimento à velhice. Campinas, SP: Autores Associados, 2016, p. 241-265.

BACICH, Lilian; MORAN, José. Metodologias ativas para uma educação inovadora: uma abordagem teórico-prática. Porto Alegre, RS: Penso, 2018.

BATISTA, Karina Barros Calife; GONÇALVES, Otília Simões Janeiro. Formação dos profissionais de saúde para o SUS: significado e cuidado. Saúde e Sociedade, São Paulo, v. 20, n. 4, p. 884-899, out./dez. 2011.

BATISTA, Sylvia Helena Souza da Silva et al. Formação em Saúde: reflexões a partir dos Programas Pró-Saúde e PET-Saúde. Interface, Botucatu, v. 19, supl. 1, p. 743-752, dez. 2015.

BRASIL. Conselho Nacional de Educação. Câmara de Educação Superior. Resolução CNE/CES n. 3, de 07 de novembro de 2001. 2001a. Institui Diretrizes Curriculares Nacionais do Curso de Graduação em Enfermagem. Disponível em: http://portal.mec.gov.br/cne/arquivos/pdf/CES03.pdf. Acesso em: 26 set. 2020.

BRASIL. Conselho Nacional de Educação. Câmara de Educação Superior. Resolução CNE/CES n. 4, de 07 de novembro de 2001. 2001b. Institui Diretrizes Curriculares Nacionais do Curso de Graduação em Medicina. Disponível em: http://portal.mec.gov.br/cne/arquivos/pdf/CES04.pdf. Acesso em: 26 set. 2020.

BRASIL. Conselho Nacional de Educação. Câmara de Educação Superior. Resolução CNE/CES n. 5, de 07 de novembro de 2001. 2001c. Institui Diretrizes Curriculares Nacionais do Curso de Graduação em Nutrição. Disponível em: http://portal.mec.gov.br/cne/arquivos/pdf/CES05.pdf. Acesso em: 26 set. 2020.

BRASIL. Ministério da Saúde. Ministério da Educação. Programa Nacional de Reorientação da Formação Profissional em Saúde - Pró-Saúde: objetivos, implementação e desenvolvimento potencial. Brasília, DF: Ministério da Saúde, 2007.

BRASIL. Ministério da Saúde. Portaria Interministerial n. 2.101, de 3 de novembro de 2005. Institui o Programa Nacional de Reorientação da Formação Profissional em Saúde - Pró-Saúde - para os cursos de graduação em Medicina, Enfermagem e Odontologia. Brasília, DF: Ministério da Saúde, 2005.

CONTERNO, Solange de Fátima Reis; LOPES, Roseli Esquerdo. Inovações do século passado: origens dos referenciais pedagógicos na formação profissional em saúde. Trabalho, Educação e Saúde, Rio de Janeiro, v. 11, n. 3, p. 503-523, set./dez. 2013.

CONTERNO, Solange de Fátima Reis; LOPES, Roseli Esquerdo. Pressupostos pedagógicos das atuais propostas de formação superior em saúde no Brasil: origens históricas e fundamentos teóricos. Avaliação, Campinas; Sorocaba, v. 21, n. 3, p. 993-1016, nov. 2016. 
CYRINO, Eliana Goldfarb et al. Há pesquisa sobre ensino na saúde no Brasil? ABCS Health

Sciences, Santo André, v. 40, n. 3, p. 146-155, set./dez. 2015.

CZERESNIA, Dina; MACIEL, Elvira Maria Godinho de Seixas; OVIEDO, Rafael Antonio Malagón. Sentidos da Saúde. In: CZERESNIA, Dina; MACIEL, Elvira Maria Godinho de Seixas; OVIEDO, Rafael Antonio Malagón. Os Sentidos da Saúde e da Doença. Rio de Janeiro, RJ: Editora Fiocruz, 2013. p. 11-26.

DUARTE, Newton. A individualidade para si: contribuição a uma teoria histórico-social da formação do indivíduo. 3.ed. rev. Campinas, SP: Autores Associados, 2013.

FACCI, Marilda Gonçalves Dias. A periodização do desenvolvimento psicológico individual na perspectiva de Leontiev, Elkonin e Vigostski. Cadernos CEDES, Campinas, v. 24, n. 62, p. 64-81, abr. 2004.

FREIRE, Paulo. Pedagogia da Autonomia: saberes necessários à prática educativa. São Paulo, SP: Paz e Terra, 1996.

FREIRE, Paulo. Pedagogia do Oprimido. 17.ed. Rio de Janeiro, RJ: Paz e Terra, 1987.

FREITAS, Cilene Maria et al. Uso de metodologias ativas de aprendizagem para a educação na saúde: análise da produção científica. Trabalho, Educação e Saúde, Rio de Janeiro, v. 13, supl. 2, p. 117-130, dez. 2015.

KOSIK, Karel. Dialética do Concreto. Trad. Célia Neves e Adorico Toribio. 2.ed. Rio de Janeiro, RJ: Paz e Terra, 1976.

LEONTIEV, Alexei. Os princípios psicológicos da brincadeira pré-escolar. In: VIGOTSKI, Lev Semenovich; LURIA, Alexander Romanovich; LEONTIEV, Alexei. Linguagem, desenvolvimento e aprendizagem. 11.ed. São Paulo, SP: Ícone, 2010.

LEONTIEV, Alexei. O desenvolvimento do psiquismo. 2.ed. São Paulo, SP: Centauro, 2004.

LONGAREZI, Andrea Maturano; FRANCO, Patrícia Jorge Lopes. A. N. Leontiev: a vida e a obra do psicólogo da atividade. In: LONGAREZI, Andrea Maturano; PUENTES, Roberto Valdés (Orgs.).

Ensino Desenvolvimental: vida, pensamento e obra dos principais representantes russos. Uberlândia, MG: EDUFU. Coleção Bibloteca Psicopedagógica e Didática, Série Ensino Desenvolvimental, 2013. p. 67-110.

LURIA, Alexander Romanovich. Curso de Psicologia Geral. 2.ed. v. I. Rio de Janeiro, RJ: Civilização Brasileira, 1991.

MARX, Karl. O Capital: crítica da economia política. Tomo I. São Paulo, SP: Nova Cultural, 1996. Disponível em: http://www.histedbr.fe.unicamp.br/acer_fontes/acer_marx/ocapital-1.pdf. Acesso em: 30 ago. 2019.

MARX, Karl; ENGELS, Friedrich. A Ideologia Alemã (Feurbach). 9.ed. São Paulo, SP: Hucitec, 1993.

OLIVEIRA, Marta Kohl. Vygotsky: aprendizado e desenvolvimento: um processo sócio-histórico. São Paulo, SP: Scipione, 1993. 
PUENTES, Roberto Valdés; LONGAREZI, Andréa Maturano. Ensino Desenvolvimental: vida, pensamento e obra dos principais representantes russos. 3 v. Uberlândia: EDUFU, 2013a, 2017, 2019.

PUENTES, Roberto Valdés; LONGAREZI, Andréa Maturano. Escola e didática desenvolvimental: seu campo conceitual na tradição da teoria histórico-cultural. Educação em Revista, Belo Horizonte, v. 29, n. 1, p. 247-271, mar. 2013b.

SAVIANI, Dermeval. Pedagogia histórico-critica: primeiras aproximações. Campinas, SP: Autores Associados, 2013.

SMOLKA, Ana Luiza Bustamante. Social practice and social change: activity theory in perspective. Human Development, Switzerland, v. 44, n. 6, p. 362-367, 2001.

VIGOTSKI, Lev Semenovich. Obras Escogidas III: problemas del desarrolho de la psique. Madrid, España: Visor, 2000.

VIGOTSKI, Lev Semenovich; LURIA, Alexander Romanovich. Estudos sobre a história do comportamento: o macaco, o primitivo e a criança. Porto Alegre, RS: Artes Médicas, 1996.

WERTSCH, James V. Vygotsky and the social formation of mind. Cambridge, MA: Harvard University Press, 1985.

Submetido: $04 / 10 / 2019$

Aprovado: 04/10/2020 